\section{EXTEND THE RANGE OF DIAGNOSTIC CAPABILITIES}

Digital Dental offers a complete range of cone beam digital imaging systems. The entry-level Uni-3D is a combined panoramic and small FOV cone beam CT system which can be upgraded with a one shot Ceph for orthodontic

\section{digitall $\mathbf{l}$.dental}

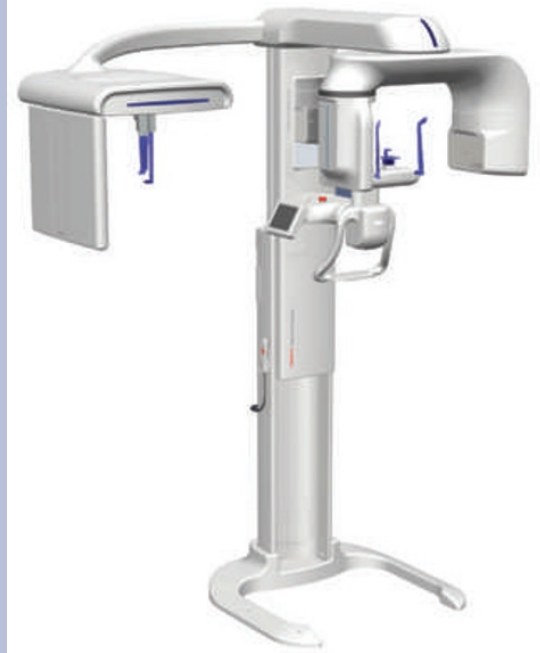

applications. It has been designed for the multi-disciplinary practice which carries out implant dentistry. The mid-range Duo 3D offers a wider selection of fields of view, with four options between $5 \mathrm{~cm} \times 5 \mathrm{~cm}$ and $12 \mathrm{~cm} \times 8 \mathrm{~cm}$.

The Reve 3D is the first system to offer free FOV ranging from $5 \mathrm{~cm} \times 5 \mathrm{~cm}$ to $15 \mathrm{~cm} \times 15 \mathrm{~cm}$. This further extends the range of diagnostic capabilities and includes various default values for greater operator convenience.

All of the systems automatically switch between the panoramic and CT sensor and can replace your existing OPG, enabling you to scan every type of image without the need to purchase more than one device.

The 3D images are viewed with the powerful EZ3D software. They deliver all the anatomical information for single up to full arch implant placement, and are ideal for precise endodontic, orthodontic and periodontal diagnoses.

Reader response number 54

\title{
COMMUNICATE MORE EFFECTIVELY WITH PATIENTS
}

The new Kodak K1500 Intraoral Video Camera from PracticeWorks features wireless connectivity (Wi-Fi), making the future of intraoral dental imaging affordable for every practice.

This stylish and state of the art equipment is designed for ease of use, with patented true autofocus technology, removing the need for constant manual adjustments. The Wi-Fi facility enables wire-free movement, with images and video transmitted to the docking station which is easily transported between surgeries.

Suitable for intraoral and extraoral examinations, the K1500 is compatible with a wide range of PCs and digital video players, helping you to communicate more effectively with patients simply capture the image or video, then display and discuss.

Captured digital files are automatically saved to PC or SD card and the free dental imaging software included with the product makes it easy to manage, store and share data.

Reader response number 55

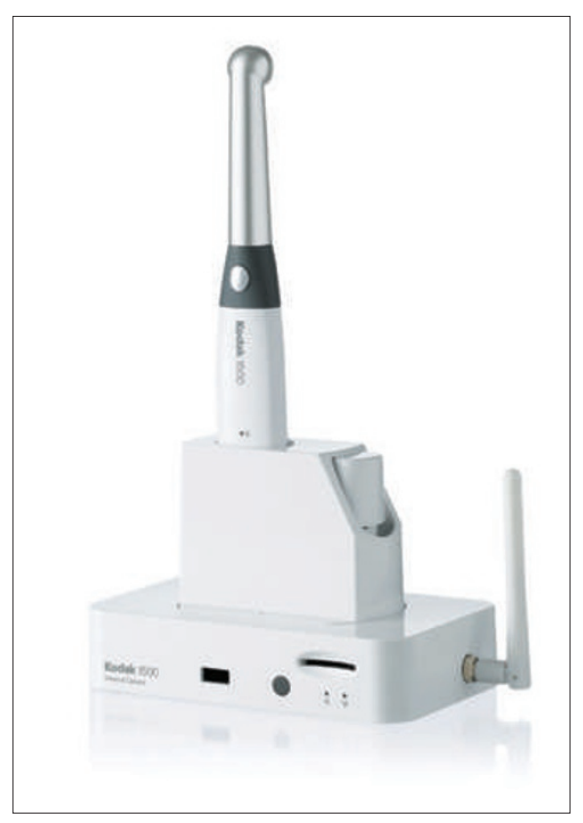

\section{PREVENT TEETH FROM CLENCHING TOGETHER}

Under Armour Performance Mouthwear has been recently launched in the UK and dentists have the chance to become authorised providers of this product. By preventing the teeth from clenching together, pressure on the temporomandibular joint is relieved.

As a result, the body produces less of the 'stress hormone' cortisol and the athlete benefits from greater focus, stamina and strength. By becoming an authorised provider of UA Performance Mouthwear, dentists can develop a whole new market for patients keen to benefit from greater athletic results.

Reader response number 56

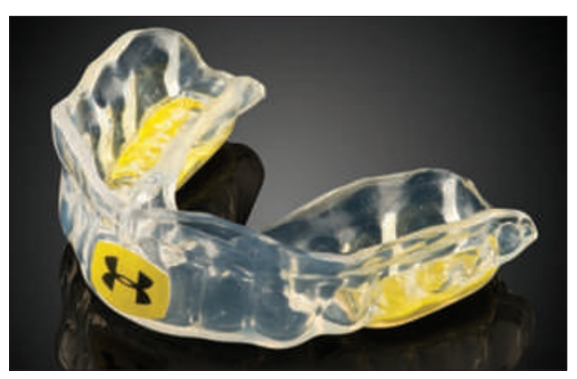

\section{NEW RESIN-MODIFIED GLASS IONOMER CEMENT SYSTEM}

To make orthodontic bonding quicker, a new addition to the range of GC Fuji Ortho resin-modified glass ionomer cements has been introduced.

GC Fuji Ortho Band is the first orthodontic cement to be made available as a paste in the special Paste Pak cartridge. The unique Paste Pak Dispenser allows for a faster and more accurate dispensing system, which minimises cement waste.

Optimal handling is guaranteed by a film thickness of just $3 \mu \mathrm{m}$, a working time of 3 minutes 30 seconds and a setting time of 3 minutes. The final colour of the paste is blue which makes identification of residual cement after de-bonding much easier and quicker. Further features include no acid etching and problem-free removal, perfect bonding in a moist environment and high fluoride release to help reduce the risk of white spots.

Reader response number 57 